\title{
Impactos de Acordos Regionais Hemisféricos sobre as Economias Brasileira e Argentina*
}

\author{
Simão Davi Silber \\ Rosana Curzel**
}

Resumo: Utilizando-se o banco de dados e modelo de equilíbrio geral computável GTAP (Global Trade Analysis Project), analisam-se os efeitos da formação de uma Área de Livre Comércio das Américas (Alca) sobre algumas variáveis da economia brasileira e argentina e estimam-se os resultados decorrentes de um estreitamento da integração Brasil-Argentina. São simulados cenários de total liberalização comercial e outro, no qual se excluem os produtos sensíveis das negociações.

Palavras-chave: Acordos Comerciais, Equilíbrio Geral Computável, Mercosul, Integração Regional, Comércio Internacional.

Abstract: This paper analyzes the effects of a Free Trade Agreement in the Americas on the Brazilian and Argentinean economies using the GTAP (Global Trade Analysis Project) Computable General Equilibrium Model (CGE). In addition, it quantifies the effects of more incoming integration between Brazil and Argentina. The simulations are based in two scenarios for each case: complete trade liberalization and a second case, when sensible products are excluded.

Keywords: Trade Agreements, Applied General Equilibrium, MERCOSUR, Regional Integration, International Trade.

\footnotetext{
* Versão modificada do artigo apresentado no VII Simpósio Internacional sobre "América Latina y el Caribe: el impacto de la crisis del ciclo neoliberal, el rol de los Estados e sus transformaciones y las modalidades de inserción internacional de la región”, organizado pelo CEINLADI/FCE/UBA, Buenos Aires, em outubro de 2006. Agradecemos aos comentários e sugestões de Joaquim J. M. Guilhoto e Eduardo A. Haddad.

** Simão Davi Silber, Professor da Faculdade de Economia, Administração e Contabilidade - FEA/USP. E-mail: sdsilber@ usp.br. Rosana Curzel, Doutoranda do Programa de Pós-Graduação em Integração da América Latina - PROLAM/USP. E-mail: rcurzel@usp.br. Recebido em 23/01/07 e aceito em 06/06/07.
} 


\section{Introdução}

O objetivo deste artigo é o de avaliar os possíveis impactos de uma liberalização comercial entre os países das Américas sobre as economias da Argentina e Brasil de maneira ampla. Ou seja, de maneira a contribuir para o debate sobre os riscos e oportunidades da Alca e considerando-se toda a economia. Em outras palavras, o interesse é investigar os diferentes impactos sobre os diversos setores econômicos brasileiros e argentinos, bem como suas conexôes com o crescimento econômico e aumento do bem-estar destes países. Para viabilizar este tipo de análise optou-se pelo uso de um modelo de equilíbrio geral computável, que possui a vantagem de permitir a visualização da interdependência entre os agentes econômicos dos países envolvidos e seus efeitos de encadeamento. $\mathrm{O}$ uso de modelos para estimar impactos de acordos regionais de comércio sobre a economia dos países intensificou-se nas últimas décadas e isso tem sido explicado por pelo menos três fatores: a maior disponibilidade e melhor qualidade dos dados estatísticos sobre o comércio, o avanço tecnológico que resultou na produção de sofisticados softwares que possibilitaram a resolução de modelos mais complexos e o processo de negociações comerciais junto à Organização Mundial do Comércio e acordos regionais e bilaterais. Tais fatores têm contribuído para o aumento da demanda por avaliaçôes sistemáticas acerca dos possíveis resultados dos acordos comerciais entre países vizinhos, paralelamente aos avanços das negociaçóes multilaterais em torno da OMC. Os temas envolvem, usualmente, a questão da diminuição da proteção dos mercados internos para determinados produtos. Isso ocorre através da eliminação e/ou diminuiçãao gradativa das barreiras às importaçôes nas mais diversas modalidades, e dos subsídios às exportaçóes e à produção doméstica.

O propósito deste trabalho é investigar quatro possibilidades de acordos de comércio para o Brasil e Argentina, concentrando-se apenas no hemisfério americano. Não se pretende fazer prognósticos sobre resultados dos acordos comerciais, mas sim um estudo preliminar sobre os efeitos obtidos num arcabouço de equilíbrio geral.

Assim, utiliza-se o modelo multirregional e multissetorial de equilíbrio geral do comércio global, ou seja, a base de dados e estrutura de modelagem do Projeto de Análise do Comércio Global (GTAP) na versão 6.2, que 
representa a economia global no ano de 2001 (DIMARANAN, 2005). Através dele são feitas quatro simulaçóes de políticas comerciais. Antes de efetuar as simulaçóes, foram feitas atualizaçóes no sistema de proteção tarifária norte-americano para setores ou produtos selecionados aplicados para alguns países das Américas. A primeira simulação considerou a formação da Área de Livre Comércio entre as Américas (Alca), na hipótese de eliminação de todas as barreiras tarifárias às importaçóes, bem como todos os subsídios à produção doméstica para todos os países da região e todos os setores considerados, excluindo-se o de serviços. O exercício subseqüente foi uma repetição do primeiro, com a exclusão de setores ou produtos julgados sensíveis. $\mathrm{O}$ terceiro considerou um estreitamento entre as relaçóes bilaterais Brasil-Argentina, portanto, eliminou todas as barreiras ao comércio entre ambos. O quarto e último repetiu o anterior e excluiu os mesmos setores da segunda simulação.

Alguns estudos se preocuparam com a mensuração dos prováveis efeitos da formação da Alca sobre os países do Cone Sul. Por exemplo, Gurgel, Bitencourt e Teixeira (2002) e, mais recentemente, Domingues e Haddad (2006).

Esses estudos demonstraram ganhos para a economia brasileira a partir da liberalização comercial. Gurgel, Bitencourt e Teixeira (2002) também se valeram do Projeto GTAP, na sua terceira versão, para simular efeitos da Alca e de um possível acordo comercial do Mercosul com a União Européia sobre algumas das economias envolvidas. Quando testaram tarifa zero para as importações em todos os países da América, eliminação dos subsídios às exportações e à produção, encontraram, dentre outros resultados, uma taxa de crescimento para o PIB real brasileiro de $2 \%$ e para o argentino, queda de $2,41 \%$. Concluíram que a criação da Alca apresentaria ganhos modestos em termos produtivos e de bem estar, contudo dinamizaria os fluxos de comércio entre os países e o Brasil, particularmente, se tornaria mais dinâmico no comércio internacional de manufaturados, pois elevaria as exportaçóes e importaçóes desse setor.

Domingues e Haddad (2006) utilizaram-se do modelo inter-regional de equilíbrio geral SPARTA (São Paulo Applied Regional Trade Analysis), desenvolvido para análise das economias paulista e brasileira, para simular 
impactos macroeconômicos, regionais e setoriais da formação da Alca. Os autores levaram em consideração as barreiras tarifárias do comércio bilateral do Brasil com Argentina, resto da Alca, Nafta, UE, Japão e restante do Mundo,- portanto, não apresentam uma liberalização tarifária completa na $\mathrm{Alca}^{1}$ - e encontraram uma variação no PIB real brasileiro de $0,086 \%$. Os autores inferem que a Alca tende a contribuir para o crescimento econômico do país e, no longo prazo, pela geração de superávit comercial. Sugerem, apesar disso, que acordos desse tipo devem ser vistos como integrantes de uma política de desenvolvimento pelo papel estratégico da inserção brasileira na economia internacional e pelos próprios benefícios econômicos advindos.

Este artigo analisa alguns dos efeitos da formação da Alca sobre a economia brasileira e argentina, considerando-se uma agregação específica de setores, com destaque para têxtil, vestuário, laticínios e arroz. Diferencia-se basicamente pelo uso da versão mais recente do Projeto GTAP, pela estratégia de agregação adotada e mudança de algumas das tarifas do banco de dados original. Além desta introdução, há outras três seçôes. Uma apresentação sumária sobre a estrutura de modelagem do GTAP, a agregação adotada dos setores e regiōes e os cenários supostos estão na próxima seção. A segunda apresenta alguns resultados e finaliza-se com comentários na última seção.

\section{O Modelo}

Trata-se de um modelo de equilíbrio geral, multirregional e multissetorial, construído pela primeira vez em 1992 e desde então atualizado anualmente. O GTAP consiste em uma base de dados mundial bem documentada e disponível publicamente, uma estrutura padrão para os modelos de equilíbrio geral, um software para trabalhar os dados e implementar o modelo padrão e uma rede de pesquisadores espalhados pelo mundo e conectados através da internet ${ }^{2}$. Além disso, o Projeto também possui um consórcio de agências internacionais cujo objetivo é fornecer uma base de suporte e capacitação aos interessados neste tipo de análise.

O conteúdo da base de dados é composto por informações sobre o

\footnotetext{
${ }^{1} \mathrm{O}$ modelo SPARTA não considera as barreiras comerciais dos outros membros do bloco, - uma vez que não se trata de um modelo global -, de modo que permanecem as mesmas.

${ }^{2}$ Maiores informações podem ser obtidas através do sítio http://www.agecon.purdue/centers/gtap.
} 
comércio bilateral, transporte e dados de proteção dos diversos setores das economias. As principais fontes dessas informaçóes são as Matrizes de InsumoProduto (MIP) individuais dos países ou, regionais, para os casos em que algum dos países não possua essa estatística. As MIP’s fornecem os elementos necessários para o conhecimento das relaçóes inter-setoriais dentro de cada país. É a partir delas que se constrói uma Matriz de Contabilidade Social, a qual agrega outros tipos de dados das economias, em geral provenientes das Contas Nacionais ou outras bases, como receitas e despesas das outras instituiçóes - famílias, governo e setor externo. Em geral, as informações macroeconômicas são provenientes do Banco Mundial, as de comércio de mercadorias, da base de dados COMTRADE e a de serviços, das Estatísticas de Balanços de Pagamentos do Fundo Monetário Internacional.

Alguns princípios regem a manutenção dessa base de dados, por exemplo, a ampla disponibilidade pública, sendo gratuita para algumas agregaçóes de países e setores padronizados, e, a preço de custo para o acesso completo aos que deseja preparar sua própria base de dados. As atualizaçóes consistem no aprimoramento das informaçóes, seja com a inclusão de novos países ou setores, sejam no tocante à própria qualidade das estatísticas. Sáo seis as versóes existentes do GTAP, sendo a última composta por 57 diferentes indústrias, 87 países ou regiōes e refletem a economia do ano de 2001. Estes são alguns dos fatores responsáveis pelo sucesso na disseminação do uso do GTAP.

\section{Estrutura}

A teoria subjacente ao modelo do GTAP é a mesma dos modelos de equilíbrio geral computável, multissetorial e multirregional. Aqui existem dois tipos de equações, aquelas que abrangem as relaçôes contábeis e que, portanto, garantem o equilíbrio entre as receitas e despesas dos agentes econômicos envolvidos, e aquelas denominadas comportamentais, baseadas na teoria microeconômica, e que descrevem a trajetória otimizadora dos agentes na economia como, por exemplo, a função da demanda, o comportamento das firmas, do mercado de fatores, a determinação do investimento agregado, etc.

A seguir apresentaremos uma visão panorâmica das relaçóes contábeis 
através do diagrama da Figura 1, desenvolvido por Brockmeier (2001). As setas representam fluxos de valores ${ }^{3}$.

Existe um agente regional, no topo da figura, para cada país ou região do Projeto GTAP. Esse agente regional é que controla as receitas e despesas geradas pela economia. A renda regional possui duas fontes básicas: receitas das firmas pelo uso dos fatores de produção $\left(V O A^{4}\right)$ e despesas com os impostos devidos por todos os agentes $(T A X)^{5}$. Essa renda é distribuída e exaurida de acordo com uma função de utilidade per capita Cobb Douglas entre os componentes da demanda final: gastos dos agentes privados (PRIVEXP), do governo $(G O V E X P)$ e a poupança $(S A V E)$. Nas primeiras versōes do modelo padrão, essas participaçóes eram constantes. No entanto, já foram feitas alteraçôes para o comportamento do agente privado, o qual segue uma função CDE (Constant Difference of Elasticity) ${ }^{6}$. Assim, o agente regional possui um equilíbrio entre as receitas e as despesas.

O segundo agente a ser observado são os produtores de bens e serviços, que representam a demanda intermediária. Suas receitas são compostas pela venda dos bens produzidos para o governo $\left(V D G A^{\top}\right)$, para o agente privado $\left(V D P A^{8}\right)$, para outros produtores $\left(V D F A^{9}\right)$ e para o setor externo $\left(V X M D^{10}\right)$. Além dessas relações, há também o financiamento da produção pela poupança global (NETINV). Este investimento é induzido pela poupança. As despesas compóem-se do pagamento pelo uso dos fatores de produção (capital, terra e trabalho), $V O A$, já mencionada, pela compra de insumos intermediários domésticos (VDFA) e importados (VIFA $\left.{ }^{11}\right)$.

O próximo agente é o Restante do Mundo ou setor externo da economia que, através da comercialização de bens e serviços, interrelaciona-se com os agentes domésticos. Sua receita é composta da venda de produtos

\footnotetext{
${ }^{3}$ Os fluxos reais possuem direção oposta e não estão visíveis, com exceção das flechas referentes às transferência dos impostos (TAXES) ao agente regional, que não possuem a contrapartida.

${ }^{4}$ Que significa "Value of Output at Agent's Price of endowment commodities".

${ }^{5}$ Em TAX também estão descontados os subsídios.

${ }^{6}$ Ver MacDougall, R. (2003). A New Regional Household Demand System for GTAP. GTAP Technical Paper, N. 20.

${ }^{7}$ Do inglês "Value of Domestic purchases by Government household at Agent's price".

8 "Value of Domestic purchases by Private households at Agent's prices".

9 "Value of Domestic purchases by Firms at Agent's prices".

10 "Value of eXports at Market prices by Destination".

11 "Value of Imports by Firms at Agent's price".
} 
separadamente para cada agente da economia doméstica: ao agente privado $(V I P A)^{12}$, ao governo $(V I G A)$ e ao setor intermediário da economia (VIFA), os produtores. As despesas deste agente correspondem ao fluxo de pagamentos dos bens adquiridos no mercado doméstico $(V X M D)$ e a transferência de renda para o agente regional doméstico equivalente à incidência de tributos sobre os bens exportados pela economia doméstica $(X T A X)$ e importados (MTAX).

A modelagem do comportamento dos gastos do governo é gerida por uma função de utilidade Cobb Douglas, cujas participações para todas as commodities são constantes. O segundo componente da demanda final, o setor privado, gasta comprando bens domésticos (VDPA) e importados (VIPA) e com o pagamento dos tributos, líquidos de subsídios (TAX). Seu comportamento otimizador é comandado por uma função CDE (Constant Difference of Elasticity) ${ }^{13}$. O último componente da demanda final, a poupança (SAVE), é integralmente destinado ao investimento (NETINV). O setor de poupança global agrega todos os fluxos regionais de poupança e o distribui para os investimentos em cada país/região. Como o modelo é estático, os investimentos não exercem impactos sobre a produção.

Antes da incidência do imposto ou concessão de subsídios ao produtor, os preços são denominados "preços dos agentes" e após obtém-se os "preços de mercado”. Tal incidência ou concessão vale também para o setor externo, no caso das importações e exportações. Assim, a intervenção no mercado doméstico é captada através das diferenças entre os preços de mercado e preços dos agentes ou entre os preços de mercado das importaçóes no mercado doméstico e o preço das importaçôes no mercado internacional (CIF).

O modelo GTAP padrão considera competição perfeita e retornos constantes de escala. Existem três fatores de produção: capital, trabalho e terra, esta utilizada apenas pelo setor agrícola. O capital é móvel internacionalmente, mas a terra e o trabalho não. Este é móvel no mercado doméstico.

\footnotetext{
12 "Value of Imports by Private households at Agent's price".

${ }^{13}$ Ver nota 5. O uso desta forma funcional distingue o GTAP dos outros modelos de equilíbrio geral.
} 


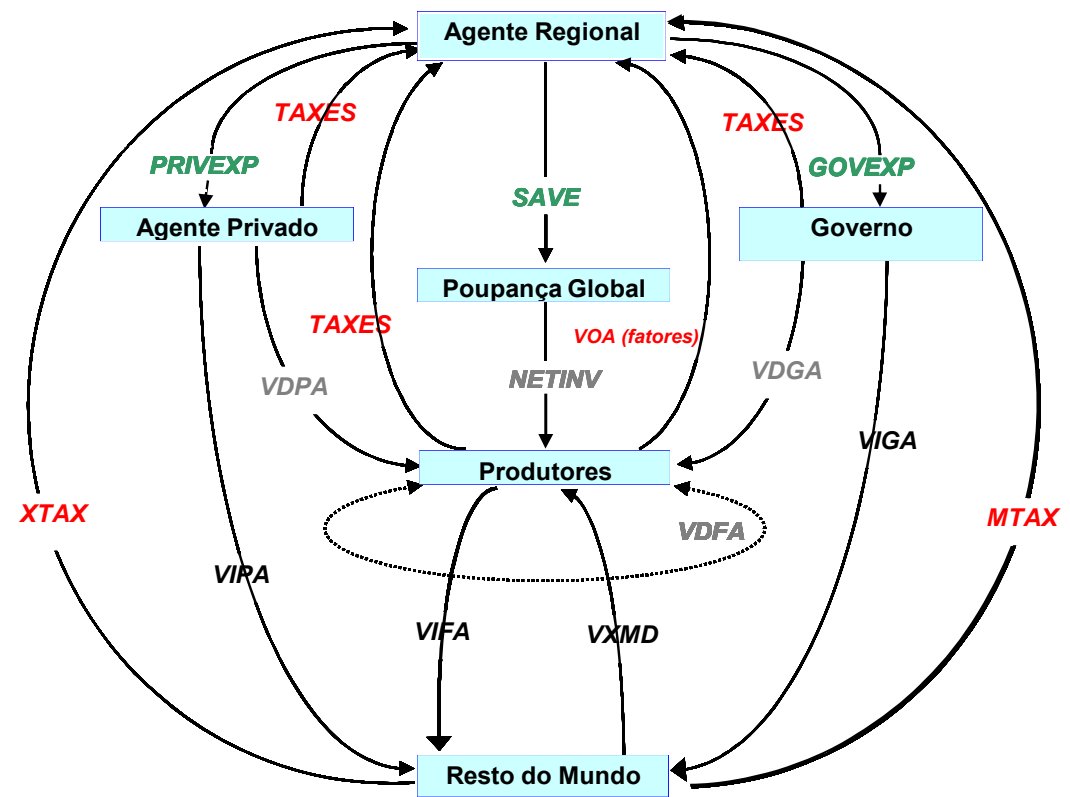

Figura 1 - Economia multirregional aberta FONTE: Brockmeier, 2001, p. 16

\section{Estratégia de agregação}

Para o propósito deste trabalho dividiu-se a base de dados em 8 regióes e 10 setores (Tabela 1). Como se pretende estimar impactos de liberalização do comércio sobre a economia brasileira e argentina, estas aparecem desagregadas e também os países da América do Norte, de modo a ressaltar os contrastes. A definição da agregação dos setores foi feita para se concentrar a atenção em alguns deles: cultivo de arroz, produtos derivados do leite, refino do açúcar, indústria têxtil e do vestuário. São setores bastante protegidos na América do Norte e têm, com exceção do arroz, elevados impostos sobre as importaçóes provenientes do Brasil e da Argentina.

É senso comum entre os usuários do programa GTAP a necessidade de se atualizar a estrutura de proteção tarifária vigente, uma vez que as alíquotas $a d$ valorem inseridas são aquelas consolidadas na $\mathrm{OMC}$, não sendo, portanto, as tarifas efetivas. Como os 57 setores da base de dados equivalem a mais de 
5 mil linhas tarifárias, o cálculo das tarifas efetivas aplicadas pelos diferentes países é tarefa prodigiosa, definiu-se a seguinte estratégia. Escolheram-se os principais produtos cujas alíquotas ad valorem aplicadas pelos Estados Unidos ao Brasil fossem as mais elevadas dentro da própria base de dados do GTAP. No caso do cultivo do arroz, a escolha deveu-se ao fato de os Estados Unidos subsidiarem sua produção em 85,7\%. Observe-se que dada a complexidade do tratamento dado ao açúcar, não foi possível calcular a taxa efetiva aplicada pelos Estados Unidos, ficando esta tarefa para trabalho posterior. Deste modo, as alterações na estrutura de proteção tarifária está apresentada na Tabela 2.

Os Estados Unidos são responsáveis por cerca de 30\% da produção mundial, - segundo a base de dados do GTAP, no ano de 2001 - a Uniāo Européia por quase 25\%, enquanto Brasil e Argentina juntos produziram apenas $2,2 \%{ }^{14}$.

Existem diferenças com relação à importância relativa de cada setor/ produto para cada região/país. Por exemplo, o setor Laticinios representa $1,85 \%$ da produção da Argentina e Brasil considerados conjuntamente, enquanto para o Nafta equivale a 1,51\%. A produção de Arroz, por exemplo, foi muito mais importante nos países do Mercosul do que nos do Nafta.

\section{Cenários}

O modelo GTAP foi utilizado para simular quatro diferentes cenários e avaliar as conseqüências nas economias argentina e brasileira. $\mathrm{O}$ primeiro (E1) considerou uma liberalização completa na formação da Alca, ou seja, eliminaram-se todas as barreiras tarifárias às importações, os subsídios à produção doméstica e às exportaçóes em todos os setores de todos os países das Américas. O segundo (E2) não liberaliza os setores do Arroz, Refino de Açúcar, Laticínios, Têxtil e Vestuário. No terceiro (E3) considerou-se uma liberalização bilateral completa entre Argentina e Brasil e no quarto (E4) excluiu-se os mesmos setores de $E 2$.

Na Tabela 3 pode-se ver o porcentual de subsídios concedidos pelos países ou regióes para cada setor ou produto agregado do modelo GTAP. É notável

\footnotetext{
${ }^{14}$ A participação do Brasil foi de 1,5\%; Canadá, 2,1\%; México e o Restante das Américas contribuíram, cada qual, com $1,8 \%$, de acordo com a base de dados do GTAP.
} 
o elevado porcentual de subsídio norte-americano à produção de arroz: 86\%, como já foi mencionado. No caso brasileiro, todos os setores agrícolas, com exceção do Açúcar, são subsidiados a taxas pequenas, porém positivas.

Omitiu-se a apresentação de todas as tarifas às importaçóes aplicadas pelos países, por origem dos produtos, por questão de espaço, mas vejam-se alguns números. O Canadá aplicou uma tarifa de $126 \%$ aos Laticínios da Argentina, 94\% aos do Brasil e 114\% aos do Restante das Américas; o México aplicou uma tarifa de 65\% aos Laticinios da Argentina e 35\% ao Vestuário do Brasil. As tarifas máximas aplicadas à entrada de produtos norte-americanos foram de cerca de $21 \%$ ao Vestuário, na Argentina e Brasil.

\section{Resultados das simulações ${ }^{15}$}

Antes da implementação dos cenários, apresentamos os valores da produção (Tabela 4), das exportações (Tabela 5) e importações (Tabela 6) de todos os setores, para todos os países e regióes aqui considerados, de modo a melhor visualizar os impactos após as simulações.

Em quase todos os casos, os Estados Unidos são os maiores produtores das Américas, exceto no arroz. Excluindo-se o Restante do Mundo, o maior produtor de arroz é o grupo de países do Restante das Américas, com 1,8\% da produção mundial, seguidos do Brasil (1,2\%) e Estados Unidos (0,9\%). Porém, os EUA são os maiores exportadores desse produto, exceto o Restante do Mundo. O grupo de países do Restante das Américas aparece quase sempre como o segundo maior produtor, com exceção dos casos do setor têxtil, onde é o México, e o setor de manufaturas pesadas, o Canadá. No setor de Laticínios, os EUA ainda são os maiores exportadores das Américas (2,7\%), seguindo-se Restante das Américas (1,4\%), Canadá (1,1\%) e Argentina (1\%), estando Brasil (0,1\%) e México (0,2\%) quase equiparados. Seria desnecessário dizer que os EUA são os maiores importadores das Américas, salvo pelo fato de que não o são nos casos do Refino do açúcar (BR) e setor do Vestuário (RA).

Feito isto, consideremos a medida de política comercial implementada neste trabalho, a da eliminação das tarifas ad valorem das importaçôes, bem como os subsídios à produção e às exportaçóes. A diminuição de uma tarifa

\footnotetext{
${ }^{15}$ Os resultados, que foram omitidos por falta de espaço, podem ser solicitados para os autores via e-mail.
} 
de importação implica diretamente na diminuição do preço doméstico desse bem no país importador. Isso vai provocar uma substituição pelo consumidor de bens domésticos por bens importados. Também vai provocar uma queda nos preços dos bens compostos de importados, de maneira que aumenta a demanda dos setores importadores desses bens. Preços baixos das importaçóes também equivalem a aumento dos lucros, que induz a uma expansão do produto. Tal aumento também induz a uma elevação da demanda por fatores primários, capital e trabalho, daí retransmitindo o resultado da liberalização para outros setores da economia.

Os ganhos projetados em termos de PIB real (Tabela 7) favoreceram todos os países das Américas, porém a taxas percentuais bastante modestas. Por exemplo, no cenário de liberalização completa (E1), o maior ganho real no PIB foi observado no Brasil, de $0,10 \%$, seguido do México (0,08\%), Argentina (0,06\%), Estados Unidos e Canadá (0,01\%) e Restante das Américas $(0,005 \%)$. As regióes com declínio no PIB real foram a Uniāo Européia e Restante do Mundo, as quais não eliminaram seus mecanismos de proteção. Com a exclusão dos setores sensíveis (E2), Brasil, México, Argentina e EUA continuaram a apresentar taxas crescentes do PIB real, porém menores que em $E 1$. Quando se focalizou unicamente no comércio bilateral Brasil-Argentina (E3), os ganhos reais no PIB foram menores ainda, porém positivos ${ }^{16}$. Vale observar que o PIB no modelo GTAP abrange os gastos das famílias, do governo, o valor da produção da firmas e o saldo da balança comercial.

As mudanças relativas nas projeções das relaçóes de troca em E1 favoreceram Argentina, Brasil, EUA e Restante das Américas, nessa ordem. Lembramos que as relaçóes de troca refletem a razão entre os preços das exportaçóes e o das importaçóes. Desse modo, os preços recebidos pelas exportaçóes foram maiores que os pagos pelas importaçóes na Argentina, Brasil em todos os cenários e EUA (E1 e E2) e Restante das Américas (E1). A liberalização favoreceu os laticinios da Argentina cuja demanda apresentou aumento expressivo em todos os países da América do Norte,

\footnotetext{
${ }^{16}$ Ganhos de 0,01\% para o Brasil e 0,05\% para a Argentina em ambos os cenários (E3 e E4), o que sugere que a exclusão dos setores Cultivo de arroz, Refino de Açúcar, Laticínios, Têxtile Vestuário não são aparentemente sensíveis no comércio entre ambos.
} 
sobretudo para Canadá e México ${ }^{17}$. Nos EUA houve aumento da demanda de laticinios argentinos de 98\%. Esse é um setor cujas exportaçóes para os países do NAFTA aumentaram demasiado, o que revela a importância de se calcular a tarifa efetiva do Canadá e México aos demais países. O Canadá, por exemplo, é desfavorecido pelas relaçóes de troca, sendo uma das razóes o fato de suas importaçóes de laticínios norte-americanos terem crescido de US\$ 131 milhôes para US\$ 836 milhóes, com aumento de cerca de 8\% nos preços dessas importaçóes. O México faz uma realocação de suas importações de laticínios, mais dos EUA para mais da Argentina: cresceram de US\$ 91 milhóes para US\$ 497 milhóes, tendo diminuído, portanto, as dos EUA, de US \$ 285 milhôes para US\$ 108 milhóes. Os preços dos laticínios argentinos aumentaram cerca de $2,4 \%$, portanto não explica integralmente as relações de troca negativas para o México, podendo ser o fato de continuarem importando arroz norte-americano - apesar de ter caído à metade - porém cujos preços aumentaram 67\%, este decerto relacionado com a queda de $86 \%$ dos subsídios à produção.

A função utilidade no modelo GTAP é representada pelo agente regional e desagregada entre os consumos privado, governamental e poupança e indica o nível de satisfação do consumo de cada instituição ou na região. A variação equivalente (Tabela 9) mede o impacto de mudanças nos preços da utilidade do consumidor, em termos monetários. Trata-se, portanto de uma medida de bem-estar e como explicam Gurgel, Bitencourt e Teixeira (2002), consiste em saber o quanto se teria de oferecer ao consumidor antes redução do preço, de modo a deixá-lo tão bem quanto após a queda. Dessa maneira, sendo o objetivo o de investigar perdedores e ganhadores após os choques de política econômica, vê-se que o maior ganhador são os Estados Unidos, seja com ou sem os produtos sensíveis. Aliás, ao excluírem-se os produtos sensíveis, os ganhos diminuem para Argentina, Brasil e EUA, sendo o grande perdedor o grupo dos países do Restante das Américas e o México é o único que apresenta aumento de bem estar.

Para a Argentina é bastante recomendável o estreitamento das relaçóes bilaterais com o Brasil pois os ganhos de bem estar (E3 e E4) representariam

\footnotetext{
${ }^{17}$ As alíquotas ad valorem aplicadas aos laticínios argentinos pelo CN e MX são de 126\% e 65\%, respectivamente, antes da ultraliberalização. Enfatize-se que tais tarifas são as consolidadas na OMC, não tendo sido possível, até o momento, ter calculado as tarifas efetivas.
} 
mais de 70\% dos ganhos que seriam auferidos com a Alca (E1). Porém, para o Brasil, tal recomendação não seria tão expressa uma vez que tais ganhos seriam de cerca de $7 \%$ apenas.

Considerando os dados apresentados, para Brasil e Argentina, os cenários de liberalização completa das Américas (E1) e excluindo-se setores sensíveis (E2), não apresentam diferenças expressivas em termos de crescimento do PIB real. Mesmo no caso das relações de trocas, os ganhos não seriam muito menores quando se excluem os sensíveis. Envolvendo-se os ganhos de bem estar reforçar-se-ia ainda mais, em tese, o apoio a uma área de comércio livre entre as Américas. Porém, é necessário que se observe o setor de serviços que, no caso brasileiro especialmente, seria o grande perdedor (Tabela 10).

\section{Comentários finais}

São conhecidas na literatura as limitações na interpretação dos resultados de um modelo de equilíbrio geral do tipo GTAP. Mais ainda, este é um trabalho em desenvolvimento, sendo a principal tarefa a do cálculo das tarifas efetivas para os produtos mais importantes nas pautas de comércio argentina e brasileira. Nosso objetivo foi o de identificar ganhadores e perdedores. Para isso foi necessário determinar um ponto de referência. Em termos de crescimento econômico (PIB), o mais favorecido foram os Estados Unidos. Porém, isso náo implicou em queda das outras economias, ao contrário, as taxas foram positivas, tendo sido negativa apenas no Restante das Américas, no cenário de exclusão dos produtos sensíveis (E2). Em termos setoriais foram identificados o setor de laticínios argentino e o setor têxtil brasileiro como fortes candidatos a serem favorecidos com a suposta liberalização comercial (E1), demonstrados pelas estimativas de superávits na balança comercial (Tabela 10). Ressalve-se que há ainda que se obter as tarifas verdadeiras de importação dos outros países, uma vez que aqui foram apresentadas apenas aquelas aplicadas pelos Estados Unidos. Em termos de bem estar para a sociedade, os resultados foram aqueles esperados, a liberalização do comércio tende a melhorá-lo. Aqui se apresentou apenas alguns dos resultados obtidos e observou-se que por tratar-se de trabalho em desenvolvimento um avanço adicional no cálculo das tarifas efetivas permitirá avançar ainda mais na análise da liberalização comercial hemisférica. 


\section{Referências Bibliográficas}

ADAMS, Philip. D. Interpretation of results from CGE models such as GTAP. Journal of Policy Modeling, v. 27, p. 941-959, 2005.

BROCKMEIER, Martina. A Graphical Exposition of the GTAP Model. GTAP Technical Paper, n. 8, 2001. Disponível em: https:/www.gtap.agecon. purdue.edu/resources/tech_papers.asp. Acesso em: 26 out. 2005.

DIMARANAN, Betina V.; MCDOUGALL, Robert A. (Ed.). Global trade, assistance, and production: the GTAP 6 data base. Indiana: Center for Global Trade Analysis, Purdue University, West Lafayette, 2005.

DOMINGUES, Edson P.; HADDAD, Eduardo A. Impactos setoriais e regionais da ALCA: projeçóes para a economia brasileira. Pesquisa e Planejamento Econômico, Rio de Janeiro, IPEA, v. 36, n. 2, p. 255-287, ago. 2006.

GURGEL, Ângelo Costa; BITENCOURT, Mayra Batista; TEIXEIRA, Erly Cardoso. Impactos dos acordos de liberalizaçáo comercial Alca e Mercoeuro sobre os países membros. Revista Brasileira de Economia, Rio de Janeiro, v. 56, n. 2, 2002.

HERTEL, Thomas W. (Org.). Global trade analysis: modeling and applications. Cambridge University Press. 1997.

LAENS, Silvia; TERRA, Maria Inês. Integration of the Americas: welfare effects and options for the MERCOSUR. Project: the Mercosur and the Creation of the Free Trade Area of the Americas, 2003. Disponível em: https://www. gtap.agecon.purdue.edu/ resources/download/1566.pdf. Acesso em: 10 jan. 2006.

LIMA, J. E. D; DE MIGUEL, C. J.; SCHUSCHNY, A. R. Acuerdos de Libre Comércio entre los países andinos y los Estados Unidos de Norteamérica: cuánto se puede esperar de ellos? CEPAL, 2006. mimeo.

USITC. United States International Trade Comission. Tariff database table. Disponível em: http://www.usitc.gov. Acesso em: jul., ago., set. 2006. 


\section{Anexos}

Tabela 1 - Agregação de países e de setores

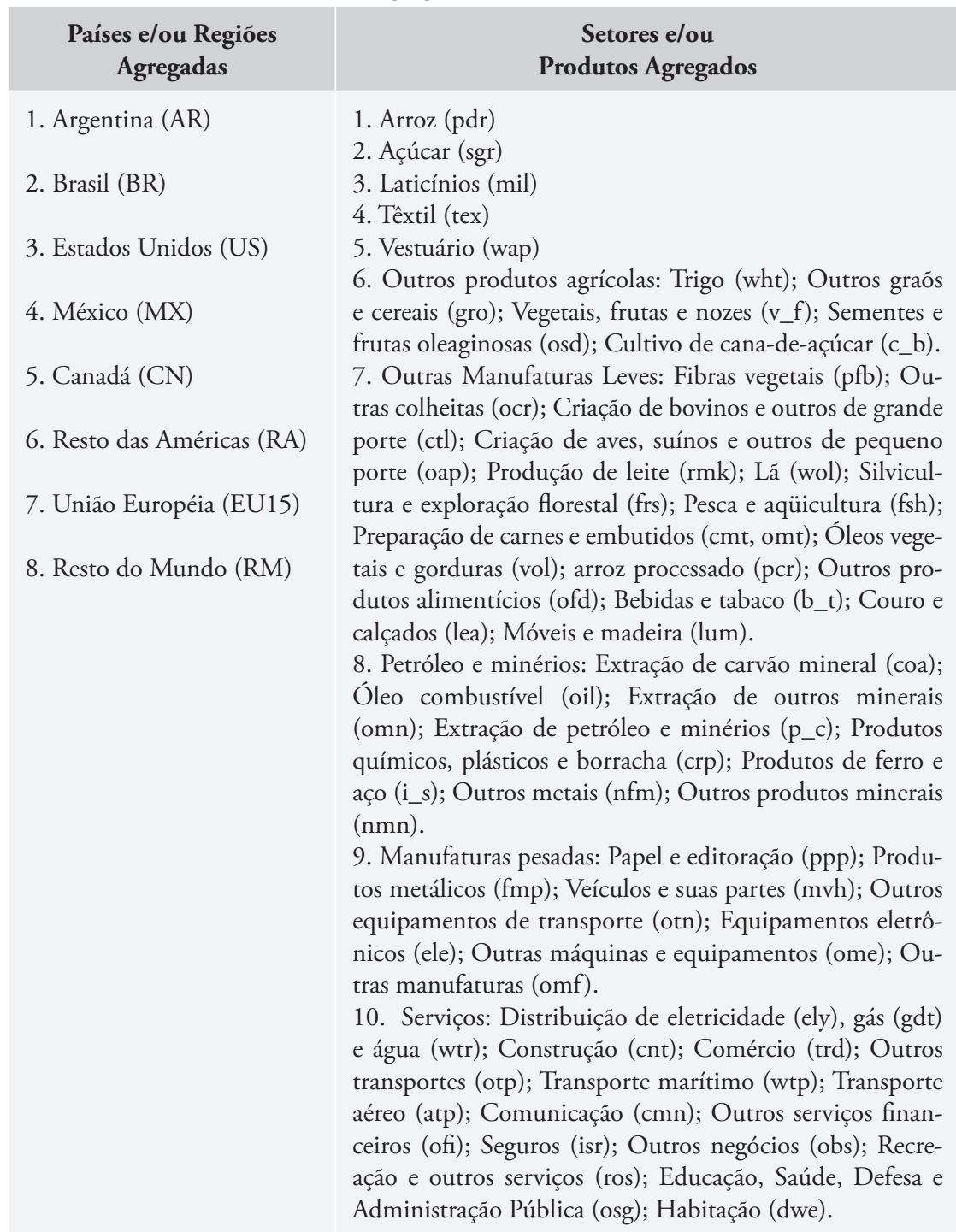

FONTE: Base de dados do GTAP. Elaboraçáo dos autores 
Tabela 2 - Estrutura de proteção tarifária dos EUA, 2001 (\%)

\begin{tabular}{|c|c|c|c|c|c|}
\hline \multicolumn{2}{|c|}{ País, Regiáo/Setores } & Laticínios & Vestuário & Têxtil & Arroz \\
\hline \multirow{2}{*}{ Brasil } & GTAP & 29,39 & 10,62 & 8,73 & 5,98 \\
\cline { 2 - 7 } Argentina & Calculada & 17,54 & 14,26 & 9,12 & 4,90 \\
\hline \multirow{2}{*}{ Canadá } & GTAP & 28,88 & 4,64 & 8,37 & 0 \\
\cline { 2 - 7 } & Calculada & 14,58 & 17,89 & 9,68 & 0 \\
\hline \multirow{2}{*}{ México } & GTAP & 13,59 & 0 & 0 & 0 \\
\hline \multirow{2}{*}{ RA } & Galculada & 8,73 & 0,43 & 0,23 & 0,47 \\
& GTAP & 3,21 & 0,081 & 0,05 & 0 \\
\hline & Galculada & 0 & 0,0111 & 0,008 & 0 \\
\hline & GTAP & 23,81 & 10,95 & 13,48 & 0 \\
\hline
\end{tabular}

FONTE: Base de dados do GTAP e USITC. Cálculo dos autores

Tabela 3 - Distorçáo na produção doméstica ou \% da taxa ad valorem de subsídios à produção na região $r-2001$

\begin{tabular}{|l|c|c|c|c|c|}
\hline \multicolumn{1}{|c|}{ Produto } & \multicolumn{3}{|c|}{ País } \\
\hline Arroz & BR & EUA & MX & CN & UE15 \\
\hline O_Prod_Agrícolas & 1,22 & 85,70 & 38,10 & & \\
\hline O_Mnfcs_Leves & 1,45 & 9,48 & 3,90 & 1,55 & 2,92 \\
\hline Mnfcs_Pesadas & & 0,27 & & & \\
\hline
\end{tabular}

FONTE: Base de dados do GTAP, 2005 
Tabela 4 - Valor da Produção, 2001 (em US\$ milhóes de 1995)

\begin{tabular}{|l|c|c|c|c|c|c|c|c|}
\hline $\begin{array}{l}\text { Setor/ } \\
\text { Produto }\end{array}$ & AR & BR & US & MX & 5 CN & RA & EU & ROW \\
\hline Arroz & 168 & 1.151 & 878 & 141 & 6 & 1.811 & 731 & 93.637 \\
\hline RefAcu & 403 & 4.848 & 30.083 & 4.759 & 262 & 6.558 & 19.655 & 63.440 \\
\hline Laticinio & 4.191 & 6.883 & 84.421 & 4.632 & 7.443 & 9.780 & 110.551 & 78.659 \\
\hline Textil & 3.049 & 11.752 & 144.713 & 20.736 & 9.189 & 19.649 & 125.439 & 435.254 \\
\hline Vest & 4.075 & 6.477 & 110.048 & 17.523 & 7.834 & 21.631 & 97.573 & 242.360 \\
\hline OPagric & 12.653 & 13.874 & 68.465 & 14.641 & 9.063 & 31.828 & 77.067 & 513.603 \\
\hline OMnfcL & 50.556 & 91.524 & 1.025 .369 & 146.515 & 108.871 & 155.282 & 1.011 .858 & 2.036 .966 \\
\hline PetMin & 39.734 & 111.090 & 1.355 .862 & 147.589 & 143.139 & 147.773 & 1.451 .013 & 3.069 .415 \\
\hline MnfcPe & 30.409 & 115.388 & 2.545 .024 & 186.031 & 220.708 & 81.092 & 2.532 .605 & 3.644 .794 \\
\hline Svces & 256.307 & 491.056 & 12.583 .909 & 507.368 & 736.648 & 565.610 & 9.177 .266 & 11.253 .920 \\
\hline TOTAL & 401.544 & 854.043 & 17.948 .770 & 1.049 .934 & 1.243 .163 & 1.041 .016 & 14.603 .757 & 21.432 .048 \\
\hline
\end{tabular}

FONTE: Base de dados do GTAP, 2005

Tabela 5 - Valor das exportaçóes, 2001 (em US\$ milhóes de 1995)

\begin{tabular}{|l|c|c|c|c|c|c|c|c|}
\hline $\begin{array}{l}\text { Setor/ } \\
\text { Produto }\end{array}$ & AR & BR & US & MX & $\mathbf{5 ~ C N}$ & RA & EU & ROW \\
\hline Arroz & 32 & 2 & 286 & 0 & 0 & 123 & 138 & 1.490 \\
\hline RefAcu & 54 & 1.484 & 350 & 112 & 163 & 1.711 & 1.201 & 3.376 \\
\hline Laticinio & 306 & 38 & 818 & 60 & 328 & 423 & 19.989 & 7.770 \\
\hline Textil & 313 & 934 & 12.639 & 4.505 & 2.715 & 4.906 & 58.305 & 113.069 \\
\hline Vest & 131 & 256 & 5.120 & 6.381 & 1.577 & 8.455 & 31.123 & 107.586 \\
\hline OPagric & 5.396 & 4.033 & 20.513 & 2.975 & 5.870 & 6.898 & 23.613 & 23.467 \\
\hline OMnfcL & 8.455 & 15.642 & 48.853 & 9.378 & 31.408 & 20.959 & 201.020 & 229.192 \\
\hline PetMin & 8.125 & 16.800 & 141.150 & 24.482 & 58.743 & 55.395 & 539.497 & 726.088 \\
\hline MnfcPe & 4.206 & 20.730 & 438.908 & 106.224 & 132.265 & 18.380 & 1.125 .102 & 1.190 .829 \\
\hline Svces & 3.986 & 8.671 & 220.260 & 11.450 & 34.165 & 29.268 & 510.712 & 429.383 \\
\hline TOTAL & 31.002 & 68.590 & 888.897 & 165.566 & 267.233 & 146.517 & 2.510 .700 & 2.832 .250 \\
\hline
\end{tabular}

FONTE: Base de dados do GTAP, 2005 
Tabela 6 - Valor das importaçóes, 2001 (em US\$ milhóes de 1995)

\begin{tabular}{|l|c|c|c|c|c|c|c|c|}
\hline \multicolumn{1}{|c|}{$\begin{array}{c}\text { Setor/ } \\
\text { Produto }\end{array}$} & AR & BR & US & MX & $\mathbf{5 ~ C N}$ & RA & EU & ROW \\
\hline Arroz & 35 & 3 & 691 & 0 & 1 & 145 & 146 & 2.050 \\
\hline RefAcu & 71 & 2.048 & 486 & 135 & 181 & 2.817 & 1.402 & 6.183 \\
\hline Laticinio & 381 & 45 & 1.091 & 72 & 435 & 522 & 21.919 & 9.976 \\
\hline Textil & 339 & 1.067 & 13.916 & 4.679 & 2.833 & 5.552 & 63.320 & 131.629 \\
\hline Vest & 149 & 288 & 5.872 & 6.536 & 1.635 & 9.588 & 33.571 & 125.022 \\
\hline OPagric & 7.851 & 6.037 & 28.952 & 3.517 & 7.304 & 9.069 & 27.027 & 32.307 \\
\hline OMnfcL & 10.243 & 19.199 & 59.432 & 10.107 & 34.217 & 23.968 & 220.387 & 272.108 \\
\hline PetMin & 9.009 & 19.063 & 152.169 & 26.105 & 61.254 & 60.883 & 569.140 & 804.419 \\
\hline MnfcPe & 4.783 & 22.581 & 459.814 & 108.338 & 135.621 & 19.594 & 1.176 .102 & 1.270 .806 \\
\hline Svces & 3.986 & 8.671 & 220.261 & 11.450 & 34.165 & 29.268 & 510.714 & 429.431 \\
\hline TOTAL & 36.846 & 79.004 & 942.682 & 170.937 & 277.644 & 161.405 & 2.623 .728 & 3.083 .932 \\
\hline
\end{tabular}

FONTE: Base de dados do GTAP, 2005

Tabela 7 - Impacto sobre o PIB real dos choques de política comercial (\%)

\begin{tabular}{|l|c|c|c|c|}
\hline \multicolumn{1}{|c|}{ País/ Experimento } & E1 & E2 & E3 & E4 \\
\hline Argentina (AR) & 0,059 & 0,05 & 0,05 & 0,05 \\
\hline Brasil (BR) & 0,099 & 0,09 & 0,01 & 0,01 \\
\hline Estados Unidos (US) & 0,012 & 0,01 & 0 & 0 \\
\hline México (MX) & 0,079 & 0,06 & 0 & 0 \\
\hline Canadá (CN) & 0,015 & 0 & 0 & 0 \\
\hline Restante das Américas (RA) & 0,005 & $-0,05$ & 0 & 0 \\
\hline
\end{tabular}

FONTE: Base de Dados do GTAP, 2005

Tabela 8 - Impacto sobre as relaçôes de troca dos choques de política comercial (\%)

\begin{tabular}{|l|c|c|c|c|}
\hline \multicolumn{1}{|c|}{ País/ Experimento } & E1 & E2 & E3 & E4 \\
\hline Argentina (AR) & 1,99 & 1,64 & 1,39 & 1,39 \\
\hline Brasil (BR) & 1,17 & 1,07 & 0,08 & 0,08 \\
\hline Estados Unidos (US) & 0,51 & 0,49 & $-0,01$ & $-0,01$ \\
\hline México (MX) & $-0,09$ & 0,06 & 0,00 & 0,00 \\
\hline Canadá (CN) & $-0,10$ & $-0,06$ & 0,00 & 0,00 \\
\hline Restante das Américas (RA) & 0,25 & $-0,44$ & $-0,02$ & $-0,02$ \\
\hline
\end{tabular}

FONTE: Base de Dados do GTAP, 2005 
Tabela 9 - Variação equivalente (US\$ milhóes)

\begin{tabular}{|l|c|c|c|c|}
\hline \multicolumn{1}{|c|}{ País/ Experimento } & E1 & E2 & E3 & E4 \\
\hline Argentina (AR) & 725 & 611 & 518 & 517 \\
\hline Brasil (BR) & 1327 & 1203 & 92 & 94 \\
\hline Estados Unidos (US) & 6782 & 6408 & -175 & -175 \\
\hline México (MX) & 328 & 440 & -17 & -17 \\
\hline Canadá (CN) & -172 & -185 & 12 & 12 \\
\hline Restante das Américas (RA) & 271 & -1256 & -47 & -48 \\
\hline
\end{tabular}

FONTE: Base de Dados do GTAP, 2005

Tabela 10 - Saldo da balança comercial, 2001 (em US\$ milhóes de 1995)

\begin{tabular}{|l|c|c|c|c|c|c|c|c|}
\hline Setor/Cenário & \multicolumn{2}{|c|}{ E 1 } & \multicolumn{2}{|c}{ E 2 } & \multicolumn{2}{c|}{ E 3 } & \multicolumn{2}{|c|}{ E 4 } \\
\hline & AR & BR & AR & BR & AR & BR & AR & BR \\
\hline Arroz & 4 & 19 & $(2)$ & $(4)$ & $(0)$ & $(4)$ & $(2)$ & 1 \\
\hline RefAcu & 14 & 75 & $(3)$ & $(80)$ & $(0)$ & $(27)$ & $(3)$ & $(26)$ \\
\hline Laticinio & 563 & 24 & $(30)$ & $(10)$ & $(27)$ & 3 & $(27)$ & 3 \\
\hline Textil & $(49)$ & 169 & $(31)$ & $(77)$ & $(35)$ & $(1)$ & $(35)$ & $(2)$ \\
\hline Vest & 14 & 78 & $(34)$ & $(31)$ & $(30)$ & $(0)$ & $(30)$ & $(1)$ \\
\hline OPagric & 122 & $(234)$ & 156 & $(219)$ & $(79)$ & $(190)$ & $(79)$ & $(192)$ \\
\hline OMnfcL & $(512)$ & 20 & $(362)$ & 115 & $(572)$ & $(115)$ & $(571)$ & $(106)$ \\
\hline PetMin & $(910)$ & $(1.478)$ & $(734)$ & $(1.327)$ & $(877)$ & $(34)$ & $(877)$ & $(40)$ \\
\hline MnfcPe & 348 & $(1.021)$ & 565 & $(751)$ & 1.641 & $(39)$ & 1.642 & $(49)$ \\
\hline Svces & $(762)$ & $(1.124)$ & $(638)$ & $(1.033)$ & $(491)$ & $(89)$ & $(490)$ & $(92)$ \\
\hline TOTAL & $(1.167)$ & $(3.473)$ & $(1.111)$ & $(3.416)$ & $(471)$ & $(497)$ & $(471)$ & $(504)$ \\
\hline
\end{tabular}

FONTE: Base de dados do GTAP, 2005 